\title{
Quality of life in the third age: key predictors of the CASP-I9 measure
}

\author{
RICHARD D. WIGGINS*, PAUL F. D. HIGGS $\dagger$, MARTIN HYDE $\dagger$ \\ and DAVID B. BLANE**
}

\begin{abstract}
This article aims to identify and analyse the lifecourse and contextual factors that influence the quality of life in early old age. We conceptualise quality of life as distinct from the factors which influence it, and employ a model of the quality of life that is derived from an explicit theory of human need. The operational measure (CASP-I9) consists of ig Likert-scaled items which cover four theoretical domains: control, autonomy, self-realisation and pleasure. A postal questionnaire was sent to 286 British people aged $65^{-75}$ years who were members of the sample for the I930s Boyd-Orr study of health and diet and who had been followed up through retrospective interviews during the late i99os. The 286 were broadly representative of their age group. The survey's response rate was 92 per cent. Respondents provided information on a number of contextual influences on their quality of life in early old age, notably social support and participation, the quality and quantity of social contact, feelings of trust and reciprocity about the local neighbourhood, health and financial security. In the analyses reported here, a series of conceptual and operational influences on quality of life in early old age is identified using block regression models. Finally, the relative impact of each predictor on CASP-I9 is examined. The findings suggest that the legacy of the past tends to be best captured by people's feelings about the adequacy of their pensions and their status as owner-occupiers as well as a feeling that the area in which they live is deprived. The quality of the social contact people describe and how close they feel to those around them will ameliorate the negative impacts of the past and the immediate environment. In addition, we must recognise that people remain vulnerable to the impact of loss: recent bereavement, and major illnesses can impact on a person's quality of life.
\end{abstract}

KEY WORDS - quality of life, Casp-ı, third age.

* City University, London.

$\dagger$ University College, London.

** Imperial College of Science, Technology and Medicine, London. 


\section{Background}

There is widespread agreement that as society changes, so also does people's experience of ageing and later life (Phillipson 1998; Gilleard and Higgs 2000; Vincent 2003). During the last century, the population structure and vital statistics of the United Kingdom changed markedly, with clear consequences for life expectancy and health (Office for National Statistics I998; Blaikie I999). Alongside the increased health and longevity of the older generation, there has been an increase in early retirement (Gruber and Wise 1999). Furthermore, the increase in the availability of occupational and private-pension provision to supplement the basic state pension means that a section of those retiring have an income that is (often considerably) more than subsistence level (Department for Work and Pensions 2000). Some authors describe these phenomena as indicators of the move into 'disorganised capitalism' (Lash and Urry 1997) or late modernity (Giddens I99I). Whatever the conceptual status of such changes, they pose serious challenges for the understanding of the lifecourse.

In a Fresh Map of Life, Peter Laslett (I996 $a$ ) portrayed four distinct 'ages' of a person's lifecourse. He represented the 'First Age' as the period of childhood dependency, the 'Second Age' as the time of independence, employment and maturity, the 'Third Age' as the period during which people are freed from work and family constraints and have time to pursue a good quality of life. Finally, he saw the 'Fourth Age' as characterised by dependence and declines in health. The focus of this paper is on people in early old age (aged around 65-74 years), who might best be described as potential members of the 'Third Age'. For many authors, the 'Third Age' is in historical terms a new lifecourse stage (Young and Schuller I99I; Midwinter I992 $a$; Laslett I996b). As Gilleard and Higgs (2002) have argued, the lives of those in retirement in fin de siècle Britain are defined by circumstances that have greatly changed from those experienced by their predecessors. The Third Age seems to be based upon and to offer a later life that is agentic and reflexive. It is based on health and leisure rather than infirmity and poverty. At the same time, older people are neither socially nor economically homogeneous (Baltes et al. 1993). This paper uses the outcome measure CASP-I9 to examine the extent to which being in the Third Age implies freedoms from family constraints and to pursue leisure activities, a time for self-realisation, and opportunities for fun (Hyde et al. 2003). Specifically, we explore the contributions of gender, ageing, lifecourse events and variations as well as contemporary contextual factors on the quality of life of a unique sample of people in early old age drawn from the I93os Boyd-Orr study of health and diet (Gunnell et al. 1996). 


\section{Conceptual framework}

Our conceptual map was developed from previous research and publications about several key potential influences on a person's quality of life in the Third Age. It represents a framework for the analyses that follow. First, we describe the theoretical foundations of our outcome measure; and continue with a brief description of each of the factors that influence or shape a person's quality of life. We argue that quality of life may be shaped by ageing, gender, the past as captured by lifetime exposure to poor accommodation and environment, as well as by markers of passage into early old age, pension provision, current housing tenure, health status and access to a car. We have collectively referred to these items as 'legacy of the lifecourse'. To capture the present context we present people's reflection of the quality of their neighbourhood and feelings of safety under the heading 'social capital'. A person's current social network is captured not only in terms of the frequency with which they communicate with family and friends but the quality of these exchanges and the closeness they derive from them. Finally, there is a domain to capture the impact of recent life events.

\section{The CASP-Ig measure of the quality of life}

We have argued elsewhere that quality of life remains under-theorised and ill-defined (Hyde et al. 2003; Higgs et al. 2003). The evidence that significant numbers of older people are living longer, healthier and more active lives requires us to rethink the way in which we conceptualise and measure quality of life in this age group. The lack of a theoretically-informed measure of quality of life in early old age has meant that for a long time it has been measured by various proxies, such as health (Bowling 1997). These proxy measures rest on an implicit set of normative assumptions about each person's quality of life and often neglect the range of experiences of people in older age. Such scales should be seen as measures of the influences on quality of life rather than measures of quality of life itself. Partly as a reaction to this criticism, recent attempts to measure quality of life have sought to emphasise the importance of subject-led accounts in the construction of measures of quality of life in early old age (Farquhar I995; Bowling 1995). Researchers seek to understand what quality of life means for each person by asking respondents to rate the most important things in their lives. This approach suffers from some of the same problems as 'expert-defined' quality of life measures, in that both tend to generate measures of the influences on the quality of life rather than of quality of life itself. 
In developing the CASP-I9 measure, the initial premise was that any quality of life measure should be distinct from the factors that influence it. This conceptualisation was derived from a theory of human need that recognises the social and biological components as equal (Doyal and Gough I99I). This 'needs satisfaction' approach assumes that quality of life should be assessed as the degree to which human needs are satisfied. Grounding the model of quality of life in this ontology enables meaningful comparisons of different quality of life scores. The model implies that although there are common basic human needs, such as food and shelter, it is equally important to recognise that being human is principally an active and reflexive process (Giddens I990; Turner 1995). Based on the range of human needs, four domains of the quality of life are conceptualised: 'control', 'autonomy', 'self realisation' and 'pleasure'. The first letter of each domain and its ig items create the acronym CASP-i9 that names the measure. 'Control' and 'autonomy' are prerequisites of free participation in society. Much gerontological research has however failed to consider the more active and reflexive dimensions of being old in an increasingly complex society in which 'post-materialist' values prevail (Inglehart 1997). The narrowness of its focus has also been criticised for ignoring the agency of older people (Gilleard and Higgs I998). It is the more active aspects of old age that we aim to map with the other two dimensions of our model, 'self realisation' and 'pleasure'.

The operationalisation of the theoretical model into the self-enumerated CASP-ig measure of the quality of life has been described in more detail elsewhere Hyde et al. (2003). Each domain consists of four or five Likert-scaled agreement items, e.g. 'I look forward to each day', and in total there are Ig items, which are summed to form the overall score. The range of the scale is from zero, which represents a complete absence of quality of life, to 57, which represents total satisfaction across the four domains. Internal-consistency analysis reveals a reliable overall measure (Cronbach's alpha $=0.7)$, which has demonstrable concurrent validity. Second-order factor analysis also confirms the structure of four domains (control, autonomy, self-realisation and pleasure), for all load on to a single underlying latent variable that represents an intrinsic measure of the quality of life. CASP-I9 has been adopted by several important studies, notably the English Longitudinal Study of Ageing (Marmot et al. 2003) and the retirement module in wave I of the British Household Panel Survey (BHPS) (Taylor 2003).

\section{Age, gender and lifecourse hazards}

Many writers have expressed a concern that the gendered dimension of ageing and older age is neglected (Bury 1995; Ginn and Arber 1999). This 
study therefore set out to discover whether a person's age and gender had any impact on their quality of life. For convenience, age was dichotomised above and below 70 years. Blane and colleagues (I998) have shown that exposure to social disadvantage, as indicated by exposure to environmental health hazards, accumulates across the lifecourse and is related in complex ways to health in early old age (Holland et al. 2000; Montgomery et al. 2000; Berney et al. $2000 a, b)$. In the light of these findings, we were interested to see if the same accumulated hazard exposures directly affect the quality of life. The hazard variables used in the present analyses refer to the domestic sphere of life ('household hazards'): the number of years of exposure to residential dampness, atmospheric pollution in the residential locality, and inadequate nutrition.

These hazards or factors are often represented by cross-sectional variables but we regard them as particular stages of processes or pathways into early old age. For example, the choice whether to retire or to continue working, current health status (poor or otherwise), car ownership or access to a car, an individual's subjective assessment of whether or not they feel that they have enough income to meet their future needs, and their current housing status (owner occupier or not), collectively mark the legacy of the past. These markers represent past decisions and the consequences, or life chances, as people negotiated their passage through life. They are sensitive to the heterogeneity of individuals in the Third Age, many of whom will have retired early, be in good health and relatively affluent (Hardy and Hazelrigg 1999; Gruber and Wise 1999; Scase and Scales 2000). Following Arber's (I99I) argument that housing tenure and car access are more sensitive to women's positions when compared with social status indicators based on male occupations, they were adopted as the indicators of social and material advantage.

\section{Social capital}

One of the fastest-growing areas of study in sociology and health inequalities has been social capital (Putnam I995; Kaplan et al. 1996; Wilkinson 1996; Kwachi and Kennedy ı997; Hawe and Shiell 2000). Its meaning and measurements are still highly contested (Muntaner et al. 2000; Cattell 200I). The measure of social capital used in the present study has been informed mainly by the ideas of Wilkinson, Putnam and Kwachi, who argue that feelings of 'trust' and 'reciprocity' at the local or community level are important for understanding health inequalities. A scale was devised to test whether these two concepts had an equally important effect on the quality of life among people in aged between 65 and 75 years. 


\section{Social networks and recent life events}

There is growing evidence that social networks and social support have an impact on a person's physical and mental health and their risk of institutionalisation (Bosworth et al. 2000; Hinkikka et al. 2000). However, the relationship between social support and measures of subjective wellbeing is inconsistent (Bowling, Farquhar and Browne I99I). Bowling (I995) reported that when asked to rate the most important things in their lives, many older people mentioned friends and family. We were interested to find out the extent to which social support influenced the quality of life in the Third Age. Following Ward, Sherman and LaGory (I984), it was believed important to measure both the quality and quantity of social contacts, and for this purpose questions were adapted from the local area study carried out by the National Centre for Social Research (Veenstra 2000). A single question to measure the extent to which our respondent's had close or confiding relationships outside those in the home was added. Finally, we felt that it was important to contextualise a person's account of their quality of life in terms of the impact of any stressful recent life events.

\section{The study sample}

Respondents were drawn from a unique sample. As children they were surveyed between 1937 and 1939 by a team of medical and nutritional scientists under the direction of Sir John Boyd Orr (Gunnell et al. 1996). This sample was drawn from i6 locations in Great Britain and comprised I,352 families. A range of social, dietary, health and anthropometric data was collected. During 1996, 99 per cent of the household records and 95 per cent of the children's medical records were retrieved from the Rowlett Research Institute and entered into an electronic database at the Department of Social Medicine at the University of Bristol. Using the National Health Service Central Register, the Office for National Statistics successfully traced 85 per cent of the children who participated in the 1937-39 study.

A stratified random sample using three childhood socio-economic categories was drawn from the traced survivors who were aged $5^{-14}$ years at the time of the original study and for whom complete records, including physical measurements, were available. Recruitment continued until there were Ioo people in each of the three strata. The 300 people represented 43 per cent of those who were invited to participate in the study: 296 of them were interviewed in their own homes during 1997-98. Retrospective information was assembled onto a life-grid (Berney and Blane 1997) with items on life since childhood (family and household, residential and occupational histories) and current social circumstances and self-reported and objective health. The sample is broadly representative of their age 
group within the British population. As children, their fathers had a social class distribution which was similar to all men aged $25^{-44}$ years in the I93I population census. In early old age, the study sample was similar socio-demographically to those aged $65-74$ years in the I99I census; and objective measures of their current health were similar to those of people aged 65-74 years in the 1995 Health Survey for England (Blane et al. I999).

In 2000 these individuals were contacted again as part of the Economic and Social Research Council's Growing Older programme. Of the 296 people interviewed in 1997, I2 had either died or were untraceable. The remaining 284 were mailed a self-completion questionnaire about their quality of life. After two reminder mailings and telephone calls, a $9^{2}$ per cent response rate was achieved. All of our analyses are based on an achieved sample of 263 people aged between $65-74$ years.

\section{Operationalising the measures}

\section{The CASP-I9 measure}

The distribution of the CASP-I9 scores is remarkably symmetrical $($ mean $=$ median $=42)$ with a slight negative skewness (range $13-57)$. The higher the score the higher a person's self-reported quality of life. Item non-response for any of the ig items forming the scale was handled using multiple imputation (Rubin I996; Hill i997). Just over 25 per cent (65 cases) had at least one missing item. The imputation procedure for this degree of missing information required us to complete the data matrix for three replicates. The analyses are then repeated for each replicate and the estimates are adjusted (Schafer I997; Schafer and Graham 2002). ${ }^{1}$

\section{Age and gender}

Women slightly outnumbered men in the sample (I40 or $53 \%$ ) and they tended to be older, for 6 I per cent were aged 70 or more years, compared with $5^{\mathrm{I}}$ per cent of the men. Overall, there was no statistical association between age and gender $\left(\chi^{2}=2.19, p<0.14\right)$. The mean CASP-I9 scores for men and women were not significantly different $(p<0.62)$, but there was a significant difference between the younger (43) and older (39) age groups $(p<$ o.oI).

\section{Household hazards}

Hazards were seen as cumulative, and the scores for each person were the summation of the number of years of exposure to each. Thus a person 
who spent one year in a damp house $($ score $=\mathrm{I})$, which was situated close to a source of industrial atmospheric pollution $($ score $=\mathrm{I}$ ), would get an exposure score of two hazard-years. The measure is age-adjusted and the length of exposure was calculated from the life-grid interviews conducted during 1997 (Blane et al. 1999).

\section{Legacy of the lifecourse}

Altogether five dichotomous items made up this domain: whether or not a person felt that they had made an adequate provision for their pension; whether or not they felt that they had a choice about when to retire; their owner occupancy status; whether or not they had access to a car; and whether or not they felt that they were in good health (denoted by the absence of a reported long-standing illness).

\section{Social capital}

The postal questionnaire items were derived from the British Household Panel Survey. Its interviewers asked each respondent to name five 'good things' and five 'bad things' about their local area. From the responses, a list was compiled of the most frequent statements among the respondents aged 65-74 years. From this list we chose a mixture of I4 positive and negative statements that we believed captured aspects of trust and reciprocity (see Table I). Respondents were asked to endorse which of the I4 items applied to their local area.

To understand the nature of this domain and to reduce the number of items for the regression analysis, an exploratory factor analysis was undertaken. The varimax rotation revealed four distinct dimensions or components, which explained over 53 per cent of the total variance. The dimensions were labelled 'misery', 'sense of community', 'deprivation' and 'affluence'. Misery is a general dimension that taps into feelings of wanting to leave the area, high levels of crime and graffiti, no sense of community and deprivation. The 'sense of community' dimension is positive and indicated by: friendly people who enjoy living in the area, people looking out for each other, and a good community spirit. The 'deprived' dimension paints a bleak assessment, and includes deprivation, graffiti, lack of safety and unfriendly [people]. Finally, 'affluent' marks out a sense of comfort: it associates with privacy, a safe place, a sense of affluence, and 'few neighbours but acceptable'. Table i presents the component loadings. Summary scores for each of the dimensions were calculated by summing the endorsements for each domain (adjusting for the sign of each loading). 
T A в L E I. Factor loadings for the I4 items describing the residential neighbourhood domain of social capital

\begin{tabular}{|c|c|c|c|c|}
\hline & \multicolumn{4}{|c|}{ Component labels and item loadings } \\
\hline & Misery & $\begin{array}{c}\text { Sense of } \\
\text { community }\end{array}$ & Deprived & Affluent \\
\hline It is a safe place to live & -0.59 & & & 0.25 \\
\hline There is a lot of graffiti & 0.68 & & 0.34 & \\
\hline I want to leave this area & 0.59 & & & \\
\hline This is an affluent area & & & & 0.84 \\
\hline I have a lot of friendly neighbours & & $0.7 \mathrm{I}$ & & -0.26 \\
\hline This is a deprived area & o.69 & & 0.36 & \\
\hline People look out for each other & & $0.7 \mathrm{I}$ & & \\
\hline There is no sense of community & 0.28 & -0.47 & & \\
\hline Good community spirit & & 0.66 & & \\
\hline There is a lot of crime in the area & 0.69 & & & \\
\hline There is a good mix of people & & 0.56 & & \\
\hline It is not a safe place to live & 0.39 & & 0.70 & \\
\hline I enjoy living here & -0.48 & 0.40 & & 0.40 \\
\hline People are unfriendly & & & 0.72 & \\
\hline
\end{tabular}

Notes: The loadings are of the factors generated by varimax rotation of the principal components of the I4 items. Loadings below $|0.25|$ are omitted for convenience.

T А в L E 2. Items used to identify dimensions of a person's social network

A. Quality

There are people who:

Do things that make me happy

Can be relied on no matter

Accept me just as I am

Give me support and encouragement

Would see that I am taken care if needed

Make me feel loved

Make me feel an important part of their lives
B. Frequency

Meetings with family members

Telephone conversations with family members Meetings with friends

Telephone conversations with friends

\section{Closeness}

Not counting the people that live with you, which of the following statements best describes how many people you have a close relationship with? lots (3), some (2), one or two (I) or none (o)

\section{Social networks}

The social network measure has three distinct dimensions: the quality of social contact (which aggregates seven dichotomy scores), the frequency of social contact (the sum of four dichotomy scores items), and the density of social contact (a single item four point scale) (Table 2). 


\section{Recent life events}

The final indicator of current circumstances asked the respondent to consider whether any major events in their lives, e.g. bereavement or illnesses, had caused stress since they were previously interviewed in 1997. These responses were dichotomised. A person who reported that their lives had become more stressful as a result of major events was accorded a score of ' $I$ '.

\section{Analysis strategy}

The operationalisation of the conceptual framework next required each domain or set of items to be entered into a multiple linear regression equation or model. The logic of the sequence had a crude temporal division on which was overlaid aspects of the local neighbourhood, friends and family, with, finally, controls for the impact of recent life events. The initial base model simply controlled for age and gender. To this was added the lifecourse hazards measure for housing and the local environment, and next the legacy of the lifecourse markers were entered followed by the social capital dimensions, social network indictors and, finally, recent events. The items for each domain were entered as a 'block'. The final model therefore achieved full coverage of the conceptual framework described above. To complete the evaluation of the final model, a stepwise regression was run to develop a more parsimonious description of the influences on the quality of life. Whilst this approach is empirically driven, it starts with the inclusion of model variables that have been scoped from a theoretical perspective.

\section{Findings}

Table 3 presents the estimated regression coefficients for each step in the analysis. Rubin's rule was adopted, that so long as all three coefficients are significant, the average provides a summary of the statistical significance (Rubin 1996). The base model for age and gender confirmed our preliminary descriptive analyses. There was a strong effect of age on CASP19, which suggests that quality of life deteriorates with age. This effect was present at all stages of the analyses whichever domain indicators were added to the model. Gender did not reveal a consistent effect although in the final model the coefficient approached significance, suggesting that once negative and positive aspects of life are controlled, there is a small 
T A B L E 3. Results of the multiple linear regression analyses for CASP-I9

\begin{tabular}{|c|c|c|c|c|c|c|}
\hline Term & Base & + Hazard & + Legacy & $\begin{array}{c}+ \text { Social } \\
\text { capital }\end{array}$ & $\begin{array}{l}+ \text { Social } \\
\text { network }\end{array}$ & $\begin{array}{l}\text { + Recent } \\
\text { life events }\end{array}$ \\
\hline Constant & 43.05 & 44.62 & $5^{0.50}$ & $47 \cdot 15$ & $39.2 \mathrm{I}$ & 39.8I \\
\hline Female & -0.33 & -0.36 & -0.28 & -0.25 & $-\mathrm{I} .59$ & $-\mathrm{I} .62 *$ \\
\hline Over 70 years & -4.25 & -4.40 & -3.87 & -3.63 & -3.37 & -2.98 \\
\hline Life course hazards & & -0.07 & -0.04 & -0.02 & -0.03 & O.OI \\
\hline Non owner & & & -0.95 & $-0.82^{*}$ & $-\mathrm{I} .04$ & - I.II \\
\hline Retirement (no choice) & & & -0.77 & $-\mathrm{I} .08$ & $-\mathrm{I} .73$ & -0.99 \\
\hline Poor pension & & & -4.90 & $-4 \cdot 3^{8}$ & -4.16 & -3.86 \\
\hline Poor health & & & $-2.23^{*}$ & $-\mathrm{I} .97^{*}$ & -2.08 & - I.88* \\
\hline No car & & & 0.47 & 0.04 & $-0.6 \mathrm{I}$ & $-0.5^{6}$ \\
\hline Misery & & & & $0.3 \mathrm{I}$ & -0.08 & -0.04 \\
\hline Community & & & & 0.66 & 0.22 & 0.05 \\
\hline Deprived & & & & $-3.9^{8}$ & -2.95 & -2.45 \\
\hline Affluence & & & & 0.05 & -0.22 & 0.05 \\
\hline Density & & & & & 0.57 & 0.57 \\
\hline Quality & & & & & 0.49 & 0.46 \\
\hline Frequency & & & & & O.OI & $-\mathrm{O} . \mathrm{OI}$ \\
\hline Recent life event & & & & & & $-5 \cdot 44$ \\
\hline R-squared & 0.05 & 0.08 & 0.17 & 0.23 & 0.35 & 0.40 \\
\hline Change in $\mathrm{R}^{2}$ & & 0.03 & 0.09 & 0.06 & 0.12 & 0.05 \\
\hline
\end{tabular}

Notes: The regression coefficients are emboldened whenever $p=<0.05$ across all replicate analyses. An asterisk (*) denotes that a coefficient approaches conventional significance $(p<0.10)$. The change in $\mathrm{R}^{2}$ indicates the increase in explained variance with the addition of the specified terms.

difference in quality of life between the sexes. The second-stage analyses revealed a modest effect for the lifecourse hazard measure over and above age and gender, but this effect faded as more variables were entered into the analysis. Among the legacy markers for the lifecourse, the subjective assessment of pension inadequacy had a persistent effect on a person's quality of life. Controlling for all other influences the absence of a good income in retirement reduced the assessment of the quality of life by four or five points. Among other markers, not being an owner-occupier had a persistently negative effect on the quality of life. Health status mattered too but only approached statistical significance when all other factors had been taken into account. Being able to choose when to retire or to continue to work can be disadvantageous but not in comparison to pension adequacy and health.

For the four dimensions of a person's perception of the local neighbourhood or their social capital, only the indicator that the area was 'deprived' had a persistent impact on quality of life: it reduced the CASP-I9 score by at least two points. Interestingly, the 'sense of community' score only attained statistical significance before the social network indicators were introduced. These latter items produced an interesting finding, that the frequency of contacts with friends and family was negatively associated 
T А в L E 4. Results of stepwise regression analyses for CASP-I9

\begin{tabular}{lcc}
\hline Term & $\begin{array}{c}\text { Regression } \\
\text { coefficient }\end{array}$ & $\begin{array}{c}\text { Standardised beta } \\
\text { coefficient }\end{array}$ \\
\hline Constant & 38.26 & - \\
Density (social network) & 0.53 & 0.28 \\
Recent life events & -5.76 & -0.26 \\
Poor pension provision & -3.94 & -0.21 \\
Non owner occupier & -1.83 & -0.16 \\
Aged over 7o years & -2.98 & -0.16 \\
Feels area is deprived & -2.07 & -0.16 \\
Quality of social network & 0.43 & 0.13 \\
\hline
\end{tabular}

Note: The coefficients are entered in order of relative importance. $\mathrm{R}^{2}=0.40$

with the perceived quality and density or closeness of these interactions. Evidently, being in contact with friends and family does not guarantee an enhanced quality of life. Some social contacts may be burdensome.

In the final model, the explained variance reached 40 per cent. Age, poor pension adequacy, poor health, the sense of living in a deprived locality, having experienced a recent life event, and stress, all combined to lower the quality of life. On the other hand, having people around who make you feel happy, who give support and encouragement, accept you as you are, take care of you and make you feel important, and the sense that you have more than a couple of close relationships combine to raise the quality of life. When all the items described in column 7 of Table 3 were entered into a stepwise multiple linear regression, these findings were further confirmed. Table 4 lists the terms of this most parsimonious model in descending order of importance (or magnitude of the standardised beta coefficients) which retains an explained variance of around 40 per cent. Above the impact of greater age, the existence of close ties is most important followed by recent life events, poor pension provision and not being an owner-occupier. Feeling that an area is deprived, and the quality of a person's social network, also have important effects irrespective of a person's age.

\section{Conclusions}

The rationale for this analysis was that socio-demographic change in the developed market economies has changed the experience of older age and hence our understanding of it. Increased longevity and early labour market exits mean that the current post-work population can no longer be characterised by ill health or poverty. Rather, for many people at this stage 
of life, the Third Age is a time for self-realisation and leisure. To understand what does and does not contribute to quality of life in early old age, it is therefore necessary to look beyond the traditional foci of health and pension adequacy. To achieve this, a measure of the quality of life that is distinct from those things that might influence it has been developed and tested. The CASP-Ig measures are grounded in a theory of need that sees biological and social components as equal constituents.

The results confirm that the quality of life is not reducible to any single factor and nor is there a simple division between the affluent and the poor. Instead many things contribute to or diminish the quality of life, and the inter-relationships are complex. In early old age, as in life itself, people cannot control the passage of time. Advancing years generally lead to a deterioration in the quality of life. Lifecourse factors played a role for our sample in terms of the current financial security and housing. Beyond this, the strong effect of deprivation in the community could be linked to feelings of isolation and entrapment, as in being afraid to go out for fear of crime. Alternatively it could be that this factor taps into some other, structural, dimension of the local area. This would support Hawe and Shiel's (2000) argument that it is the material elements of social capital, rather than its relational dimension, that is important.

Veenstra's (2000) finding about the negative association between the frequency of social contacts with friends and family and health was replicated, which leads us to conclude that social contact per se should not always be seen as beneficial. Indeed it may even be a source of conflict and stress for some people. What is important for this age group is the closeness one feels to one's social network and the quality of support that one gets from it. In crude measurement terms, a strong sense of closeness in relationships may counteract the impact of major life events. But the odds for poor quality of life increase as disadvantages in health, housing and pension provision are experienced by an individual. There seem to be some obvious signs for policy intervention both at a community and individual level. Improvements in the physical environment, such as crime reduction, may improve self-confidence and trust. If people can be encouraged to look out for one another, the quality of people's social networks may improve enough to offer support when times get hard.

One clear conclusion for those seeking to improve the quality of life of this age group is that a person's current quality of life is not predetermined by their history. Although there are important lifecourse effects and these continue into later life, it is never too late to act to improve those things that contribute to the quality of life. Furthermore, this suggests that quality of life is linked to the ability to participate in the culture of the Third Age. Our analyses appear to confirm this idea. Thus, improving those things 
that facilitate older people's participation in society and combat the discrimination that some older people still face are the keys to improving their quality of life (Midwinter $1992 b$ ).

\section{Acknowledgements}

This study was funded by the Economic and Social Science Research Council through the Growing Older programme (grant L4802540r6). The authors wish to thank Lee Berney, Chris Gilleard, Maria Evandrou, Katrina Hilari, Aubrey McKennell, and Roger Thomas for their invaluable assistance as members of the Advisory Group, and Age Concern Scotland and Age Concern England for their help in setting up the focus groups. Finally, our sincere thanks to all the members of the Boyd Orr cohort, whose participation made this study possible.

\section{NOTE}

I For an illustration of the method, see Bosworth et al. (2000).

\section{References}

Arber, S. 1991. Class, paid employment and family roles: making sense of structural disadvantage, gender and health status. Social Science and Medicine, 32, 425-36.

Baltes, P. B., Mayer, K. U., Helmchen, H., Steinhagen-Thiessen, E. I993. The Berlin Aging Study (BASE): overview and design. Ageing \& Society, I 3, 483-515.

Berney, L. R. and Blane, D. B. I997. Collecting retrospective data: accuracy of recall after 50 years judged against historical records. Social Science and Medicine, 45, I5I9-25.

Berney, L., Blane, D., Davey Smith, G., Gunnell, D., Holland, P. and Montgomery, S. $2000 a$. Socioeconomic measures in early old age as indicators of previous lifetime exposure to environmental health hazards. Sociology of Health and Illness, 22, 4I5-30.

Berney, L., Blane, D., Davey Smith, G. and Holland, P. $2000 b$. Life course influences on health in early old age. In Graham, H. (ed.), Understanding Health Inequalities. Open University Press, Buckingham, 79-95.

Blaikie, A. 1999. Ageing and Popular Culture. Cambridge University Press, Cambridge.

Blane, D., Montgomery, S. and Berney, L. I998. Social class differences in lifetime exposure to environmental hazards. Sociology of Health and Illness, 2o, 532-6.

Blane, D. B., Berney, L. R., Smith, G. D., Gunnel, D. J. and Holland, P. r999. Reconstructing the lifecourse: health during early old age in a follow up study based on the Boyd Orr cohort. Public Health, I I 3, II7-24.

Bosworth, H. B., Siegler, I. C., Olsen, M. K., Brummett, B. H., Barefoot, J. C., Williams, R. B., Clapp-Canning, N. E. and Mark, D. B. 200o. Social support and quality of life in patients with coronary artery disease. Quality of Life Research, 9, 829-39.

Bowling, A. 1995. The most important things in life: comparisons between older and younger population age groups by gender: results from a national survey of the public's judgements. International fournal of Health Sciences, 6, I69-75.

Bowling, A. I997. Measuring Health: A Review of Quality Of Life Measurement Scales (2nd edition). Open University Press, Buckingham. 
Bowling, A., Farquhar, M. and Browne, P. I991. Life satisfaction and associations with social network and support variables in three samples of elderly people. International Fournal of Geriatric Psychiatry, 6, 549-66.

Bury, M. 1995. Ageing, gender and sociological theory. In Arber, S. and Ginn, J. (eds), Connecting Gender and Ageing. Open University Press, Buckingham, I5-30.

Cattell, V. 200r. Poor people, poor places and poor places: the mediating role of social networks and social capital. Social Science and Medicine, 52, I50I-I6.

Department for Work and Pensions 2000. The Pensioners' Income Series: 1999/200o National Statistics. Her Majesty's Stationery Office, London.

Doyal, L. and Gough, I. I99I. A Theory of Human Need. Macmillan, Basingstoke, Hampshire.

Farquhar, M. 1995. Elderly people's definitions of quality of life. Social Science and Medicine, 4I, I439-46.

Giddens, A. I99o. The Consequences of Modernity. Polity, Cambridge.

Giddens, A. I991. Modernity and Self-Identity: Self and Society in the Late Modern Age. Polity, Cambridge.

Gilleard, C. and Higgs, P. I998. Older people as users and consumers of health care: a third age rhetoric for a fourth age reality. Ageing \& Society, $\mathbf{1 8}, 233-48$.

Gilleard, C. and Higgs, P. 200o. Cultures of Ageing. Prentice Hall, London.

Gilleard, C. and Higgs, P. 2002. The third age: class, cohort or generation? Ageing \&尺 Society, 22, 369-82.

Ginn, J. and Arber, S. I999. The politics of old age in the UK. In Walker, A. and Naegele, G. (eds), Politics of Old Age in Europe. Open University Press, Buckingham, I68-77.

Gruber, J. and Wise, D. A. I999. Introduction and summary. In Gruber, J. and Wise, D. A. (eds), Social Security and Retirement Around the World. University of Chicago Press, Chicago, I-I8.

Gunnell, D. J., Frankel, S., Nanchahal, K., Braddon, F. and Davey Smith, G. I996. Life course exposure and later disease: a follow up study based on a survey of family diet and health in pre war Britain (I937-I939). Public Health, I 1 o, 85-94.

Hardy, M. A. and Hazelrigg, L. E. I999. Fuelling the politics of age: on economic hardship across the life course. American Sociological Review, 65, 570-6.

Hawe, P. and Shiell, A. 200o. Social capital and health promotion: a review. Social Science and Medicine, 5I $87 \mathbf{I}-85$.

Higgs, P., Hyde, M., Wiggins, R. D. and Blane, D. 2003. Researching quality of life in early old age: the importance of the sociological dimension. Social Policy and Administration, 37, 239-52.

Hill, M. 1997. Missing Values Analysis 7.5. SPSS Incorporated, Chicago.

Hinkikka J., Koskela, T., Kontula, O., Koskela, K. and Viinamäki, H. 200o. Men, women and friends: are there differences in relation to mental well being? Quality of Life Research, 9, $84 \mathrm{I}-5$.

Holland, P., Berney, L., Blane, D., Davey Smith, G., Gunnell, D. J. and Montgomery, S. M. 200o. Life course accumulation of disadvantage: childhood health and hazard exposure during adulthood. Social Science and Medicine, 5o, I285-95.

Hyde, M., Wiggins, R. D., Higgs, P. and Blane, D. B. 2003. A measure of quality of life in early old age: the theory, development and properties of a needs satisfaction model (CASP-r9). Aging and Mental Health, 7, 86-94.

Inglehart, R. 1997. Modernization and Postmodernization: Cultural, Economic and Political Change in 43 Societies. Princeton University Press, Princeton, New Jersey.

Kaplan, G. A., Pamuk, E. R., Lynch, J. W., Cohen, R. D. and Balfour, J. L. I996. Inequality in income and mortality in the United States: analysis of mortality and potential pathways. British Medical Fournal, 31 2, 999-1003.

Kwachi, I. and Kennedy, B. P. 1997. Socio-economic determinants of health: health and social cohesion. Why care about health inequality? British Medical Fournal, 31 4, I037-45. 
Lash, S. and Urry, J. I997. The End of Organised Capitalism. Blackwell, London.

Laslett, P. 1996a. A Fresh Map of Life (2nd edition). Macmillan, London.

Laslett, P. I996 b. What is old age? Variation over time and between cultures. In Cassell, G. and Lopez, A.D (eds), Health and Mortality Among Elderly Populations. Oxford University Press, New York, 2I-39.

Marmot, M., Banks, J., Blundell, R., Lessof, C. and Nazroo, J. (eds) 2003. Health, Wealth and Lifestyles of the Older Population in England: The 2002 English Longitudinal Study of Ageing. Institute for Fiscal Studies, London.

Midwinter, E. 1992 a. Leisure: New Opportunities in the Third Age. The Carnegie Inquiry into the Third Age, Carnegie Third Age Trust, Dumfermline, Fife.

Midwinter, E. 1992 b. Citizenship: from Ageism to Participation. Carnegie Inquiry into the Third Age, Carnegie Third Age Trust, Dumfermline, Fife.

Montgomery, S., Berney, L. and Blane, D. 2000. Pre-pubertal growth and blood pressure in early old age. Archives of Disease in Childhood, 82, 358-63.

Muntaner, G., Lynch, J. and Smith, G. D. 2000. Social capital and the third way in public health. Critical Public Health, ro, 107-24.

Office for National Statistics i998. Social Focus on Older People. Office for National Statistics, London.

Phillipson, C. 1998. Reconstructing Old Age: New Agendas in Social Theory and Practice. Sage, London.

Putnam, R. D. I995. Bowling alone: America's declining social capital. Fournal of Democracy, 6, 65-78.

Rubin, D. 1996. Multiple imputation after 18 years. Fournal of the American Statistical Association, 91, 473-89.

Scase, R. and Scales, J. 200o. Fit and Fifty. Economic and Social Research Council, Swindon, Wiltshire.

Schafer, J. L. I997. The Analysis of Incomplete Data. Wiley, New York.

Schafer, J. L. and Graham, J. W. 2002. Missing data: our view of the state of the art. Psychological Methods, 7, I47-77.

Taylor, M. (ed.) with Brice, J., Buck, N. and Prentice-Lane, E. 2003. British Household Panel Survey User Manual. Volume A, Introduction, Technical Report and Appendices. UK Data Archive, University of Essex, Colchester, Essex.

Turner B. 1995. Aging and identity: some reflections on the somatisation of the self. In Featherstone, M. and Wernick, A. (eds), Images of Aging, Routledge, London, 245-6o.

Veenstra G. 200o. Social capital, SES and health: an individual level analysis. Social Science and Medicine, 5o, 6r9-29.

Vincent, J. 2003. Old Age. Routledge, London.

Ward, R. A., Sherman, S. R. and LaGory, M. I984. Subjective network assessments and subjective well being. Fournal of Gerontology, 39, 93-Iог.

Wilkinson, R. G. 1996. Unhealthy Societies: The Afflictions of Inequality. Routledge, London.

Young, M. and Schuller, T. I991. Life after Work: The Arrival of the Ageless Society. Harper Collins, London.

Address for correspondence:

Accepted 29 January 2004

Richard Wiggins, Department of Sociology, City University, London EGIV OHB.

e-mail: r.d.wiggins@city.ac.uk 